\title{
Assessing mathematics within advanced school science qualifications
}

Mary McAlinden and Andrew Noyes

University of Greenwich, University of Nottingham

\begin{abstract}
Following sustained discussion regarding the relationship between advanced mathematics and science learning in England, the Government has pursued a reform agenda in which mathematics is embedded in national, high stakes A-level science qualifications and their assessments for 18year-olds. For example, A-level Chemistry must incorporate the assessment of relevant mathematics for at least $20 \%$ of the qualification. Other sciences have different mandated percentages. This embedding policy is running in parallel with an adding policy that is encouraging all young people to include the study of mathematics to 18 . In this paper we present a detailed scrutiny of the published sample assessment materials in the new A-level Physics, Chemistry and Biology qualifications in order to consider what the impact of this policy move might be for the teaching and learning of mathematics, its applications in upper secondary school advanced science studies and the implications in the transition to mathematically-demanding undergraduate studies.
\end{abstract}

\section{Keywords}

Mathematics, science, A-levels, assessment, qualifications, transition

\section{Introduction}

Educational transitions are rarely straightforward and the systemic changes between different phases of education present learners with considerable challenges: the school-university interface is one such transition point. While there is a mass of general research on transitions from primary to secondary education (Hargreaves \& Galton, 2002), at age 16 (Ball, Maguire, \& Macrea, 2000) and the move to university (Briggs, Clark, \& Hall, 2012; Hulme \& Wilde, 2014) the focus on mathematics is less well evidenced, though there are good examples at each stage: from primary (Noyes, 2006); to upper secondary or high school (Mendick, 2008; Rice, 2001); and, to university (Hernandez-Martinez et al., 2008). Sometimes studies of this transition focus on learners (Pampaka, Williams, \& Hutcheson, 2012) and other times they are more concerned with (STEM) curriculum continuity (Royal Society, 2011). The studies of transition between schools often talk of the importance of three things: 1) curriculum continuity, 2) cross-institution liaison and 3) data transfer (Nicholls \& Gardner, 1999). Our focus here is on mathematics 
curriculum and learning at the interface between schools and universities. Unlike the studies of disciplinary transitions mentioned above, the difficulty with considering mathematics at this interface is the sheer complexity of the multiple pathways for mathematics learning and application. If this were only a one-to-many relationship it would be complex enough (i.e. mathematics for a range of studies in high/moderately mathematically demanding disciplines) but, taking into account the growing interest in within-discipline learning of mathematics in schools, the relationship is becoming many-to-many.

A growing body of research and grey literature is focusing attention on the mathematics needs of learners in upper secondary education (ACME, 2011; Noyes, Wake, \& Drake, 2011) and in the transition to a host of different undergraduate study contexts (D. Harris et al., 2015; Hodgen, McAlinden, \& Tomei, 2014). Concerns about post-16 mathematics participation remain (Hodgen, Pepper, Sturman, \& Ruddock, 2010; Kounine, Marks, \& Truss, 2008; Noyes \& Adkins, 2016b) and have been a focus of attention by the Government (Noyes \& Adkins, 2016a), the British House of Lords (2012), subject associations and think tanks (J. Harris, 2012). In a recent study Adkins and Noyes (2016) examined the impact of completing A-level Mathematics upon biology and chemistry degree outcomes and found that having A-level Mathematics had no statistically significant effect on the likelihood of achieving a first class degree, which raises a number of interesting questions for researchers and educators. These concerns about the importance of mathematics (and STEM more generally) as a driver of economic growth and sustainability are not confined to England but resonate across Europe, the US and elsewhere in the developed world (Gago, 2004; National Academies, 2007; National Strategic Review of Mathematical Sciences Research in Australia, 2006).

There are two important policy ideas relevant to this discussion. The first of these, the adding policy, is that all students in England should study mathematics to 18. This was first mooted publicly in a report by the Confederation of British Industry (CBI, 2009) but has grown in momentum (ACME, 2012; J. Harris, 2012; Hodgen, Marks, \& Pepper, 2013; Vorderman, Budd, Dunne, Hart, \& Porkess, 2011). The hopes for achieving 'maths for all', a goal first championed by the then Secretary of State for Education (Gove, 2011) and reiterated in the UK Government's March 2016 budget, are heavily dependent upon new Core Maths qualifications (Browne et al., 2013). Secondly, qualification reforms are aiming to ensure that the mathematical demands of the disciplines are appropriately reflected in reformed pre-university qualifications for 18-yearolds. The earlier reports by the Nuffield Foundation (2012) and SCORE (2012) pushed in this direction and in 2014 the Department for Education made the move official when the qualifications regulator (Ofqual) was tasked with implementing a reform programme in which 
mathematics would be assessed in science A-levels (DfE, 2014). This second policy move, the embedding policy, is the focus for the remainder of this paper.

Given this change to assessment, the present research set out to investigate the ways in which three national awarding organisations have implemented this embedding policy in the three most common science A-levels: Physics, Chemistry and Biology. For awarding organisations to be accredited to offer these qualifications their assessment strategies and Sample Assessment Materials (SAMs) must be acceptable to the qualifications regulator Ofqual. As such, sample assessment materials must give an accurate impression of the nature, scope and demand of the qualifications on offer. Although these SAMs are not live papers, they are the earliest and closest indication of what the cohorts to sit these examinations will experience. As such they provide important messages to those developing classroom teaching and preparing students for the qualifications. In a linked paper we explore mathematics at the transition to university across a wider range of disciplines with a focus on international perspectives (McAlinden \& Noyes, 2017). Before we detail the methodology we set out the qualifications context in more detail.

\section{The qualifications framework in England}

In England, young people complete their General Certificate of Secondary Education (GCSE) qualifications at age 16. Typically, they study around 10 GCSE subjects and if they achieve five or more 'good grades' at C or above (otherwise referred to as Level 2) including English and mathematics they can progress to further academic study. The vast majority of students on advanced study pathways from age 16-18 choose a narrow selection of 3 or 4 A-level subjects (Level 3). From 2000, students were able to exit the A-level qualification at the half way point with an Advanced-Subsidiary (AS) qualification. Around $50 \%$ of girls and $40 \%$ of boys in each national cohort of just over 600,000 are on such A-level pathways. In mathematics, schools and colleges normally require students to have attained at least a GCSE Mathematics grade B before progressing to study the A-level (Matthews \& Pepper, 2007), though many schools prefer an A or A* grade. Over 200,000 students in each cohort gain a GCSE Mathematics grade $\mathrm{C}$ or above and then cease their study of mathematics (ACME, 2011). Some of these will study A-level sciences and of those, some will progress to university degrees without A-level mathematics (see Adkins and Noyes, 2017). Concerns about this mathematically disengaged group have precipitated the aforementioned Core Maths qualifications. These were designed to consolidate GCSE Mathematics with an emphasis on problem solving and the application of statistics.

The A-levels are national high-stakes qualifications that form the basis of school league tables and university entrance criteria. They have been in existence for well over sixty years and although they continue to evolve they remain remarkably resistant to change, though whether student attainment at this level has dropped is a different matter (Jones, Wheadon, Humphries, \& 
Inglis, 2016). What has changed is the number of organisations allowed to offer them. In the 1990s the qualifications market was rationalised to form three main awarding organisations for England's schools. These compete for market share which helps to create a highly conservative and risk averse system in which it would be a poor business move to make assessments too challenging or unpredictable given the high stakes nature of the qualifications for students and schools.

The Department for Education mandates curriculum content and devolves regulatory powers to Ofqual. They in turn set the rules for awarding organisations to qualify as fit to administer any one qualification. A raft of qualification and assessment reforms in recent years has put great pressure on this regulatory system and the changes have not always been well coordinated, for example in the timing of GCSE and A-level Mathematics reforms (Noyes, Wake, \& Drake, 2013). In this paper we scrutinise the publicly available SAMs from the three main awarding organisations for new A-levels in physics, chemistry and biology, the first examinations of which will take place in the summer of 2017.

\section{Methodology}

The remainder of this paper focuses on detailed scrutiny of three A-level science qualifications from each of the three main awarding organisations in England that we anonymise as A, B and C. Each of the qualifications comprises three examination papers which are designed to be taken at the end of the two year programme of study when students are aged 18 . The law requires the inclusion of a minimum proportion of mathematics assessment relevant to the subject of study: $40 \%$ for physics, $20 \%$ for chemistry and 10\% for biology (DfE, 2014). The assessment for each subject is based solely on the examinations, although there is also an accompanying practical endorsement.

Our approach to scrutinising this work builds upon work conducted as part of the Mathematics Pathways Project (Noyes, Drake, Wake, \& Murphy, 2010) and although the context here is slightly different, the broad principles are similar. This paper also follows on from qualitative work to which the authors contributed which focused on the position of statistics across a wider set of reformed A-levels (RSS/ACME, 2015).

Two expert researchers independently rated the mathematical content of each question across all examination papers in a given science qualification on a number of variables as set out in Table 1. Each researcher brings different perspectives to this analysis which is a strength of the approach, though a degree of subjectivity in our judgement making remains. We approached this process carefully, taking time to moderate our processes and reach consensus regarding the category definitions. We then analysed the papers independently and followed up the few areas 
of disagreement in dialogue. As will be shown below, the many small judgements get combined as we are primarily interested in the bigger picture as distinct from the data dots, rather as in pointillism.

Table 1: Recording grid for analysis of mathematics in questions. As an example, the first few columns have been completed.

\begin{tabular}{|c|c|c|c|c|c|c|}
\hline & & Question PART & 1 & 2 & 3 & 4 \\
\hline \multirow{4}{*}{ Structure } & \multicolumn{2}{|c|}{ Total number of marks per part } & 5 & 2 & 3 & 2 \\
\hline & \multicolumn{2}{|c|}{ Likely maths marks in part } & 5 & 2 & 2 & 1 \\
\hline & \multicolumn{2}{|c|}{ Part dependence } & 2 & $\mathbf{0}$ & $\mathbf{0}$ & 2 \\
\hline & \multicolumn{2}{|r|}{ Maths explicit? } & $\mathbf{1}$ & 1 & $\mathbf{1}$ & 1 \\
\hline \multirow{7}{*}{ Content } & \multirow{7}{*}{ Domain } & Numerical & 0.7 & 0.5 & $\mathbf{1}$ & 0.5 \\
\hline & & Ratio & & 0.5 & & \\
\hline & & Algebraic & & & & \\
\hline & & Graphical & 0.3 & & & \\
\hline & & Geometric & & & & \\
\hline & & Statistics \& Probability & & & & 0.5 \\
\hline & & Other & & & & \\
\hline Demand & \multirow{2}{*}{\multicolumn{2}{|c|}{$\begin{array}{r}\text { level of mathematics } \\
\text { Representing }\end{array}$}} & $\mathbf{B}$ & $\mathbf{A}$ & $\mathbf{S}$ & $\mathbf{S}$ \\
\hline \multirow{5}{*}{$\begin{array}{l}\text { Process } \\
\text { skills }\end{array}$} & & & & & & \\
\hline & \multicolumn{2}{|r|}{ Analysing - reasoning } & 0.6 & & 0.3 & \\
\hline & \multicolumn{2}{|r|}{ Analysing - procedural } & 0.3 & 1 & 0.7 & 1 \\
\hline & \multicolumn{2}{|r|}{ Interpreting } & 0.1 & & & \\
\hline & \multicolumn{2}{|r|}{ Communicating } & & & & \\
\hline \multirow{9}{*}{ Task Type } & \multirow{3}{*}{ Context } & Pure/theoretical & & 1 & & \\
\hline & & Pseudo-practical & 1 & & 1 & \\
\hline & & Experimental/practical & & & & 1 \\
\hline & \multirow{3}{*}{$\begin{array}{l}\text { Mathematical } \\
\text { complexity }\end{array}$} & no decisions needed & & & & \\
\hline & & some decision required & & & 1 & 1 \\
\hline & & $\begin{array}{ll}\text { synthesis } \\
\end{array}$ & 1 & 1 & & \\
\hline & \multirow{3}{*}{ Embedding } & low & & & & 1 \\
\hline & & medium & 1 & & & \\
\hline & & high & & 1 & $\mathbf{1}$ & \\
\hline
\end{tabular}

Despite the appearance of a rigorous, scientific approach to this analysis it is important to note a number of challenges, choices and conventions. Many of the analytic decisions involve a degree of judgement. We assume that it is the ideal student who responds to the question as intended by the question writer and achieves full marks. In other words, we asked 'what is the question intended to assess?' That said, on several occasions we found that we could approach an individual question in different ways and despite having access to the mark schemes, we retained this ambiguity and averaged our responses.

While our analysis focussed on the mathematics within each question, it was not always easy to distinguish between science and mathematics assessment. Indeed, in many questions these were 
intertwined. The 'likely maths marks in (question) part' was not easy to establish in some cases, particularly where the level of embedding in a disciplinary context was high. In our analysis we did allow fractional mark allocations, in an attempt to capture the proportion of mathematical content more accurately.

The 'part dependence' category intended to distinguish questions which where self-contained or standalone from those which had a dependence on previous and/or subsequent parts. Here it should be noted that part dependence within a question did not necessarily correspond to scaffolding of the mathematics.

For the most part, questions involving mathematical content did require the use or application of some form of mathematical work and as such we categorised these questions as being 'maths explicit'. However, we found a few instances of questions which had an undoubted reliance on mathematical information or a mathematical idea but which did not necessarily involve doing much with the mathematics. In such cases we recorded the question as 'maths not explicit'. Under 'demand' we categorised questions according to content demand rather than cognitive demand. The categories of Standard (S), Underlined (U) and Bold (B) refer to the content categories used in the reformed GCSE Mathematics (DfE, 2013) which we have used as the reference point for this work. The newly reformed GCSE Mathematics will be examined for the first time in 2017. As such, the first cohorts of students who will take the reformed science Alevels, under consideration here, will not have taken this particular qualification. However, it will be the new GCSE Mathematics qualification going forward. The remaining demand category, which we have designated as Advanced (A), refers to mathematics post-GCSE. In our analysis we have not made the distinction between whether the material would be more accurately described as AS-level, A-level or neither.

For the purposes of internal consistency the mathematical content domains (e.g. numerical, algebraic, etc.) are also taken from the reformed GCSE Mathematics content specification (DfE, 2013). The 'ratio' category we have used is not at the same level of hierarchy as the other content areas in our grid. We included it as we took the view that it was important to consider the extent of proportional reasoning required within questions. The mathematical 'process skills' used in our analysis are those commonly used in mathematical modelling or the problem solving cycle.

The inclusion of 'context' in our grid is important because of the removal of practical work assessment in the recent qualification reforms. Our categories therefore try to tease out whether questions assess the kinds of skills that could have been learned and assessed in practical science. So, for example, a real-life scenario which was not set within the context of an experimental 
situation that a student would be likely to meet was categorised as 'pure/theoretical'. The term 'pseudo-practical' was used to describe questions which were presented within a practical setting but which could easily have been rewritten without any practical context. By contrast only those questions considered to involve the assessment of practical skills, or the analysis of experimental data, of the type that a student would be likely to encounter in a laboratory situation, were recorded as 'experimental/practical'.

The classifications of 'mathematical complexity' and 'embedding' require careful clarification. A question categorised as 'no decisions needed' was considered to be a one/two-step procedure which could have been practised. We considered these questions to be distinct from those which required 'some decisions' involving some form of mathematical reasoning or choice of approach. By contrast, questions categorised as requiring 'synthesis' were those which required several independent mathematical processes to be combined in some way to reach the final solution. It is key to emphasise here that we were specifically looking for synthesis of mathematical processes and not a synthesis of mathematics and subject content which we referred to as embedding. A question with 'low embedding' was one which could be answered with little or no knowledge of the science subject i.e. in essence a question requiring only mathematical knowledge. By contrast 'high embedding' was used to describe questions in which there was a high degree of entanglement between the science subject content and the mathematics. In particular, it would be impossible to access the mathematical work without the science subject knowledge.

Grids for each paper for each of the awarding organisations' qualifications were completed independently before being moderated and synthesised. For each question the marks allocated to individual categories were distributed according to the likely proportions of different types of mathematics content, thinking, etc. required. As an example, the first four columns of Table 1 have been completed.

The moderation was carried out in two stages. The first stage involved the moderation of our results as we progressed through our analysis for each qualification, on a subject by subject basis. The second stage involved a further moderation in which we reviewed our results across all qualifications in those categories where we felt that there could have been the potential for a drift in our judgements. This was achieved by a cross-sectional approach in which we scrutinised categories in isolation across the 27 papers in the three sciences and then followed up with any necessary modifications.

One awarding organisations has an A-level Physics qualification with two examination papers and a section $\mathrm{A}$ of the third examination paper which are taken by all students entered for the qualification. For the Section B of the third examination paper a range of optional specialist 
topics are on offer. Since the experience of this Section B part of paper 3 will not be equivalent for all students we have chosen to omit this Section B from our analysis. The rationale for this decision is based on our overarching objective of determining the characteristics of the common mathematical experience shared by all students. The alternative approach of analysing all of the Section B options and aggregating the results would lead to an analysis which is pertinent to no student and as such we have discounted this option. Such optional choices are probably determined at the curriculum level, most likely by schools and teachers, so that for students any semblance of optionality may well be absent.

\section{Analysis, results and discussion}

For the purposes of this paper we have combined question-level analysis for each variable, for each awarding organisation for each science subject. This allows for comparisons between awarding organisations as well as between subjects. The charts in Figure 1 incorporate a large volume of data and the reader is invited to take time to familiarise themselves with the general patterns before proceeding to read the discussion below. We decided to present these as stacked percentages as this helps to maintain anonymity of awarding organisations. Although this enables some comparisons between the sciences it must be borne in mind that the figures in the charts are percentages of the mathematics that we found in a given qualification but that the proportion of mathematics is different in each subject (see below).

\section{Meeting statutory requirements}

The regulatory requirements for the reformed science A-levels specify prescribed minimum percentages for mathematical content for the qualification at level 2 or above:

In each AS and A-level, the assessment of quantitative skills will include at least 10\% level 2 or above mathematical skills for biology and psychology, $20 \%$ for chemistry and $40 \%$ for physics. These skills will be applied in the context of the relevant subject. (DfE, 2014, p. 24)

As part of the process of qualification accreditation awarding organisations will have been required to justify how their SAMs meet these requirements. However, information about the details of this process is not in the public domain. As such, it is difficult to compare the similarities and/or differences between our approach and that adopted by awarding organisations and the regulator Ofqual. 
BIOLOGY
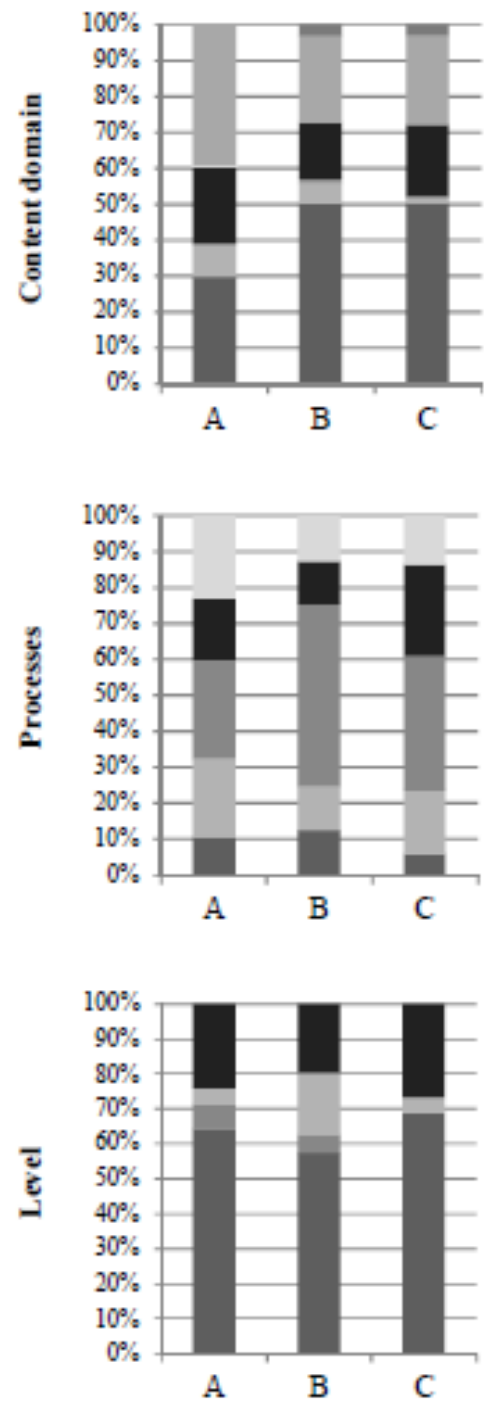

CHEMIISTRY
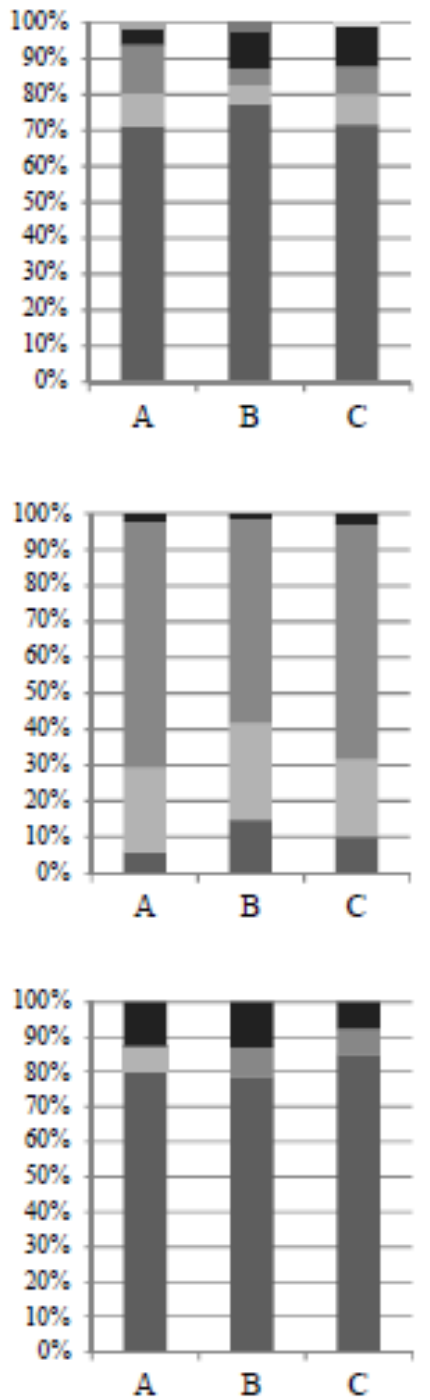

PHYSICS
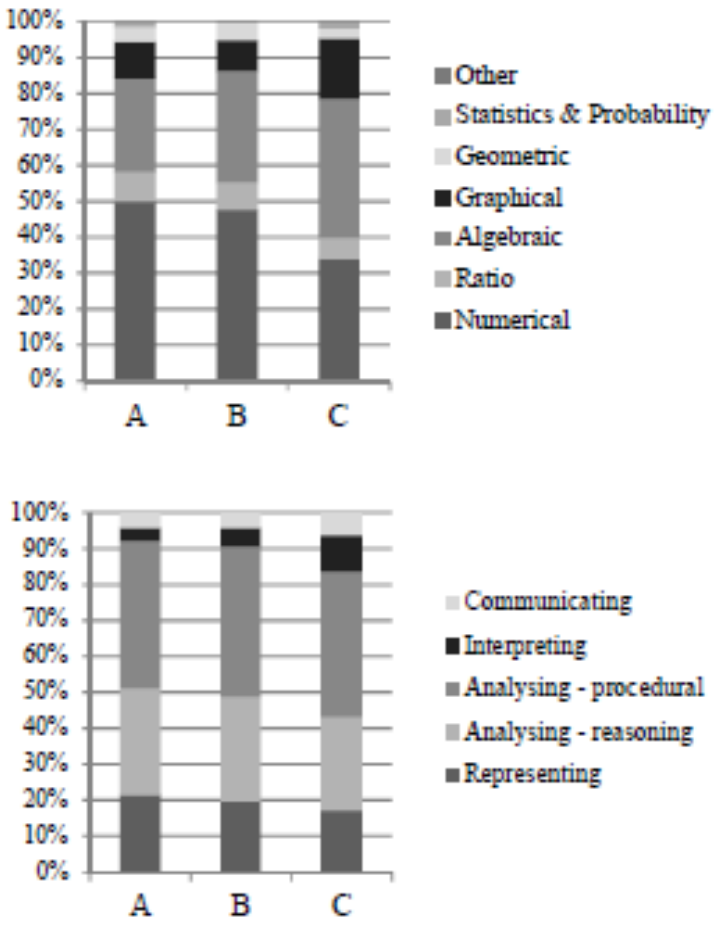

= Communicating

\section{-Interpreting}

- Analysing - procedural

In Analysing - reasoning

n Representing

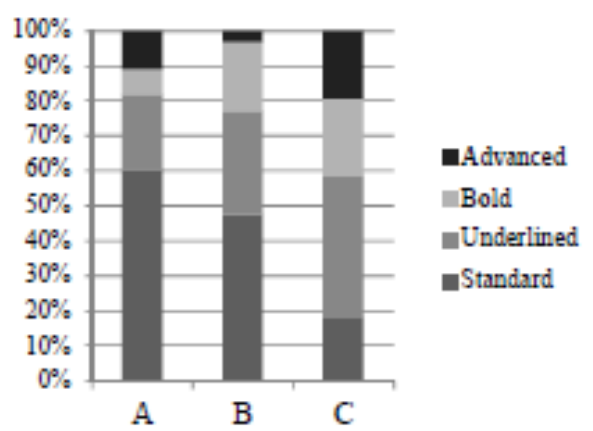

Figure la. Stacked percentage charts showing the mix of mathematical content domain, processes and level for each qualification within each science subject 
BIOLOGY
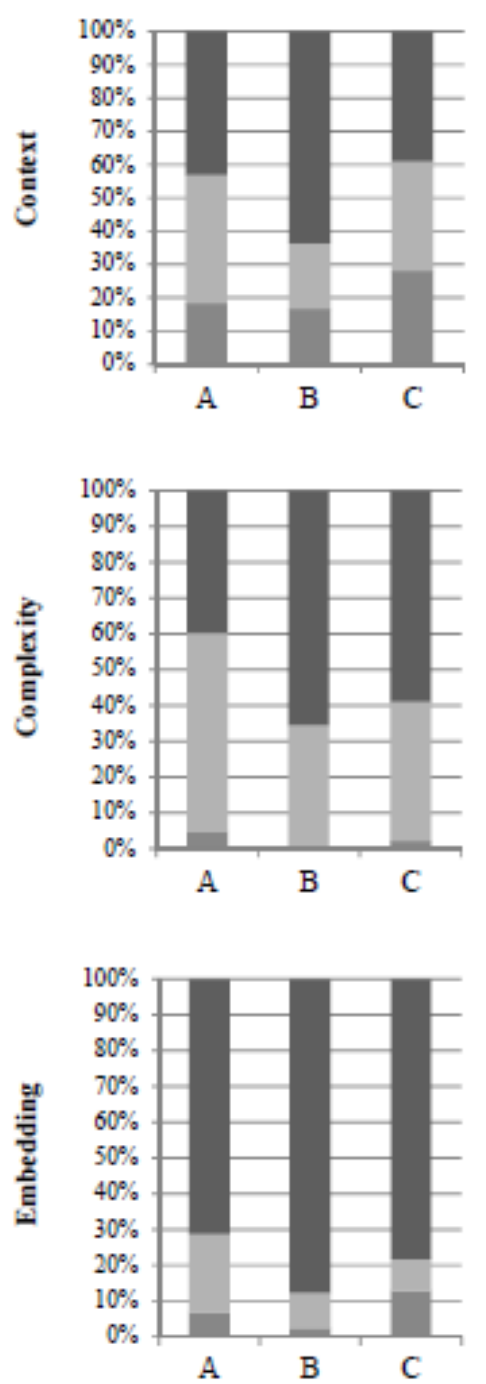

CHEMISTRI
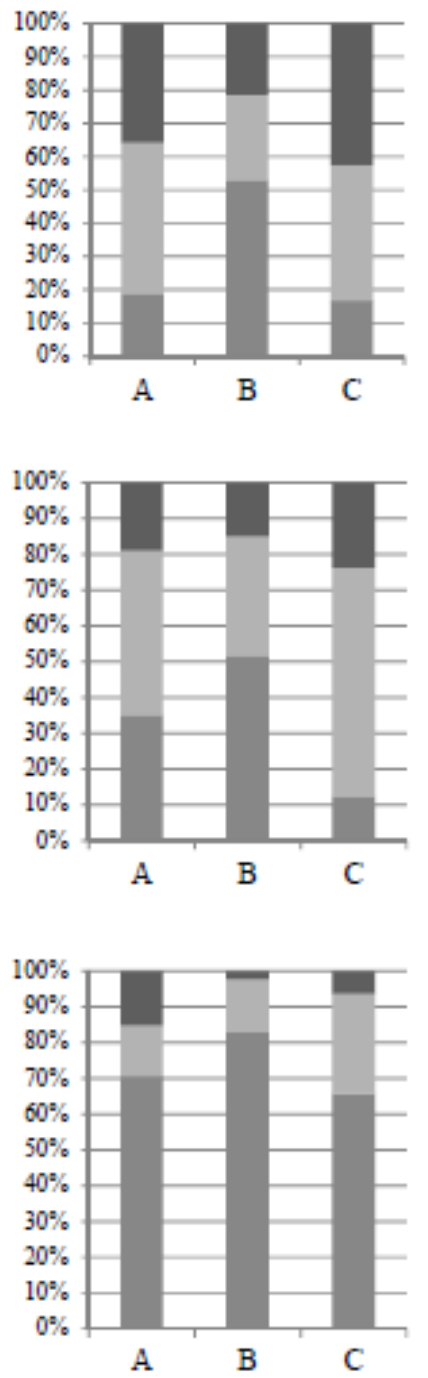

PHYSICS

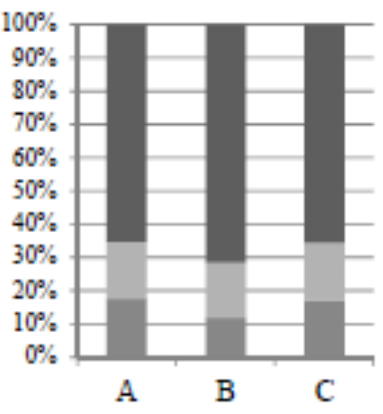

\section{Q Pure/theoretical}

Pseudo-practical

-Experimental practical

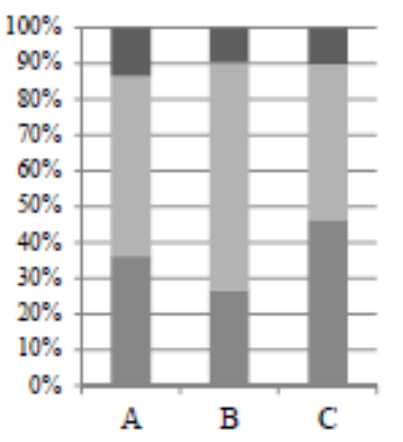

\section{no decisions needed}

some decision required

synthesis

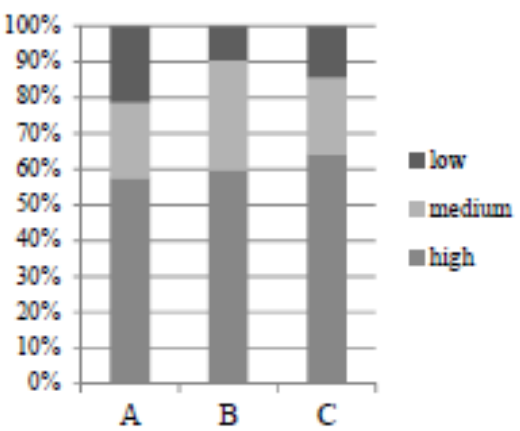

Figure lb. Stacked percentage charts showing the mix of context, levels of complexity and embedding for each qualification within each science subject 
For each qualification our analysis yielded two figures for the mathematical content: (i) the estimated total number of marks for mathematical work (EMW); and (ii) the total number of marks for questions which involved some mathematical work (EMQ). We consider the EMW to be a more accurate reflection of the true mathematical content of a qualification, although we recognise that the rules of definition for regulation may not necessarily preclude the EMQ approach.

Our categorisation of mathematical demand of the qualifications has deliberately not attempted to determine the level-2-ness or otherwise of a given question. The cumulative nature of mathematics is such that the application of mathematical content at one level may implicitly require the application of mathematical work at lower levels, which makes the precise determination of level-2-ness extremely difficult.

The results from our analysis show that for all three sciences, the qualifications offered by the three awarding organisations well exceed the required mathematical percentages, when using the EMQ measure. The EMW percentages were in the following ranges: chemistry (21\% to $24 \%$ ), biology (15\% to $22 \%$ ) and physics (36\% to $43 \%$ ). As such, for the EMW measure both chemistry and biology exceed requirements but not all physics qualifications reach the requisite $40 \%$ threshold. All physics qualifications had a series of multiple choice questions each carrying one mark (less than $1 \%$ of the qualification as a whole). In the majority of these questions, where mathematical work was involved, we attributed only half of the mark to mathematical work, the other half being allocated to the underpinning physics. We recognise that this level of granularity may be beyond that to which awarding organisations were required to comply and that using a different approach might bring all physics paper above the $40 \%$ threshold on the EMW measure.

\section{Between-subject comparisons}

Before embarking on a detailed critique of the findings of our analysis it is constructive to say at the outset that we expect the nature of the mathematical work to vary substantially across the three sciences. Indeed there is no reason to expect otherwise (DfE, 2014; SCORE, 2012). In order to make sense of this data the charts in Figure 1 need to be read in combination. Below we set out some key observations.

Mathematical content and processes: The mathematical content domain profiles we obtained from the SAMs differed substantially across the three sciences, although all relied heavily on numerical work. The combined contribution to mathematical work of the numerical, ratio and lgebraic content was over $78 \%$ in physics and over $87 \%$ in chemistry across all awarding 
organisations. By contrast there was much greater variation in biology with the corresponding proportions varying between $39 \%$ and $57 \%$. All subjects had a small percentage of proportional reasoning and geometry arose very infrequently in any of the qualifications. While algebra was almost non-existent in biology, it arose more frequently in chemistry but was a key component of physics. In our analysis, the algebraic content in physics was one area where we observed notable differences between awarding organisations (accounting for between $26 \%$ and $39 \%$ of the total mathematical content). All subjects contained some graphical work, but biology differed considerably from the other sciences in having higher percentages of statistical work. This is indicative of a more definite focus on data usage and analysis, as could be expected in biological experimental work. However, we did note that some of this statistical work was highly scaffolded. Within this context it is worth noting that the boundaries between some of the mathematical content domains (e.g. (i) graphical and (ii) probability and statistics) were not always strongly delineated and on occasions did require a judgement call within our analysis.

Regarding mathematical processes, chemistry showed a remarkable degree of uniformity across awarding organisations with over $84 \%$ of the mathematics in the qualifications attributed to a combination of procedural and reasoning analysis. Across the awarding organisations over 57\% of the mathematics was procedural in nature. Biology had a greater emphasis on communication and interpretation. In physics a more balanced distribution across the mathematical processes was observed. This is consistent with the greater overall emphasis on the full problem solving cycle which was evident in some of the physics examination questions.

Mathematical demand: As might be expected, the mathematical content within all the three science A-levels was predominantly at GCSE level. In chemistry this was almost all at standard level (GCSE) with a greater variation in biology. The requirements within physics were different with a much more marked need for the higher level GCSE material (i.e. more underlined and bold content).

All three science A-levels demonstrated only a limited reliance on advanced mathematics with some form of exponentials/logarithms being required in each subject area. Within physics, some of this content also arose in conjunction with graphical work. In biology the advanced mathematics content was largely statistical in nature. The way in which this advanced mathematics arose in the qualifications needs clarification. On many occasions it could most accurately be described as an awareness of a topic (e.g. a particular statistical test, or a natural logarithm) or a few discrete ideas about a topic rather than a coherent, transferable and widely applicable knowledge and understanding of mathematical content. 
Mathematical complexity and embedding: A prevalent feature of many of the A-level Biology mathematical questions was low mathematical complexity with minimal mathematical decision making being required. There was almost no mathematical synthesis and the mathematical work which did arise was frequently not highly embedded within a biological content. As such there were marks within the qualifications which could easily be gained by a non-biologist with a sufficient mathematical background.

By contrast, the mathematics in physics and chemistry required much more decision making and was more usually highly embedded within the discipline with relatively fewer marks which could be attained without disciplinary knowledge. Formulae were widely used in both subjects but in different ways; in chemistry the emphasis was on substitution into formulae while physics required much greater mathematical synthesis which sometimes involved the manipulation and selection of formulae following the representation of information in a suitable mathematical form.

Mathematical context: In all three science subjects we noticed differences between awarding organisations in the amounts of mathematical experimental/practical work and pure/theoretical work. In physics the high proportions of mathematical pure/theoretical work can be attributed both to questions requiring only theoretical knowledge as well as to more authentic applications of the subject that were presented within real-life contexts. We did not consider the latter to be experimental.

Perceived mathematical difficulty: The analysis shown in Figure 1 presents differing mathematical profiles across the awarding organisations. Moreover, as we carried out our analysis our overall individual responses to qualifications did suggest that there were differences in their mathematical difficulty. This prompts the question of how to explain such perceptions of mathematical difficulty within our framework of analysis. The answer is not straightforward. We consider that for a student the greatest level of mathematical challenge will arise in questions where mathematical work is highly embedded, requires mathematical synthesis, is reliant on high levels of mathematical representation and reasoning and makes use of mathematics beyond standard level GCSE Mathematics. However, while our focus has been on mathematical work, this represents only one aspect of any given qualification. As such the overall difficulty of any qualification will also be highly dependent on the broader assessment of disciplinary knowledge and understanding within the qualification as a whole.

Mathematical portraits: At this point, it is constructive to try and combine the points above in the form of subject portraits of the assessment of mathematics within the science A-levels. These are based on observations from our analysis of the SAMs and not on any judgement about 
whether or not they represent the optimal, desirable experience for a student. Indeed, they do highlight some weaknesses, which we expand on further in the next section. We also recognise that this particular set of SAMs cannot be expected to assess all mathematical content and a different set of SAMs might present a slightly different picture. We would expect live papers to be selective in the content they include with an expectation that the full content would be assessed over a longer qualification cycle.

\section{The mathematics in A-level Biology SAMs}

The low embedding of the mathematics within the qualification makes it relatively straightforward to access i.e. the biology is not complicated by the mathematics. There is a much greater emphasis on procedural work rather than mathematical reasoning and there is virtually no mathematical synthesis. The majority of the mathematical work relies only on standard level GCSE Mathematics and would be accessible to students with grades $\mathrm{C}$ and above at GCSE. The greater focus on interpreting is associated with the proportion of statistics and graphical work, although new statistical tests are generally well scaffolded. There is a high proportion of numerical work with little or no algebra.

\section{The mathematics in A-level Chemistry SAMs}

The mathematics within the qualifications is deeply embedded and so is not easily accessible without knowledge of chemistry. The mathematical work is predominantly procedural with most marks coming from questions requiring decisions to be made. The majority of the mathematics requires only standard level GCSE Mathematics although the complexity of calculations is greater than what would be expected at GCSE. It is predominantly numerical, with smaller amounts of algebra and graphical work also being required.

\section{The mathematics in A-level Physics SAMs}

In these qualifications the mathematics is very strongly embedded within the physics. Mathematical decision making and synthesis are dominant with very few marks allocated to questions requiring no decisions. There is a much greater emphasis on the full problem solving cycle, including representing, interpretation and communication with a balance between procedural and reasoning activity. While there is little advanced mathematics content, the expectations around algebraic thinking and fluency and graphical reasoning are demanding and more typical of the highest GCSE grades.

Our analysis is of course based on scrutiny of the SAMs and not on the learning experiences of students following these subjects. A desirable aim of including mathematical assessment within these qualifications could be the stimulation of relevant mathematics learning. It remains a moot 
point as to whether or not this will be achieved. Indeed, in the past this has been an area where pre-reform qualifications were seen to be deficient (Koenig, 2011, 2012).

\section{Concluding comments}

In thinking about the mathematical aspects of qualifications in the sciences it is important that these are not considered in isolation. Embarking upon, and succeeding in, an A-level qualification in a science subject is only one step in a potentially much longer learner trajectory. The mathematical preparedness of students acquired through GCSE Mathematics and the subsequent maintenance and development of mathematical fluency and competency during Alevel study are both important factors. However, so too is the preparation that such A-level qualifications offer for future study and employment. The breadth and scope of the latter is too wide to consider here so we focus instead on progression into university study within the science disciplines themselves. Nevertheless, we do recognise that for many students science subjects offer routes into a wide variety of university degree programmes.

Our analysis has shown that the mathematical demands of chemistry and biology are substantially different from those in physics. In our analysis we identified almost no algebraic content in the SAMs for A-level Biology. This is particularly noteworthy given that a 2011 study identified that algebra was one area of mathematics that was taught within UK undergraduate biosciences degrees, and was identified as "an area of particular difficulty" for undergraduate students (Koenig, 2011, p. 4). The study pre-dates the most recent qualifications reforms and algebraic manipulation is clearly specified in the new requirements for A-level Biology (DfE, 2014).

At the time of the development of the new Core Maths qualifications biology was considered as one subject area which could be served mathematically by Core Maths; chemistry was not (Browne et al., 2013). The proposed focus of the Core Maths qualification on the consolidation of GCSE Mathematics, problem solving and statistics could potentially make Core Maths a useful supporting mathematical qualification for biology, though whether it would produce the algebraic competence and confidence for future biologists is moot given their early stage of development and implementation.

The situation for chemistry is somewhat different. Our analysis has shown that A-level Chemistry requires only limited mathematical content beyond GCSE Mathematics. As such, at first sight, any level 3 study of mathematics would certainly provide additional and valuable support for A-level Chemistry. However, this does not represent the full picture. The mathematical requirements of chemistry at university go beyond those we have observed in our 
analysis and include topics such as calculus (Shallcross \& Yates, 2014). As such an AS-level in Mathematics (or indeed an A-level), which incorporates some calculus, would offer better preparation for further study in the discipline than Core Maths (Hodgen, McAlinden \& Tomei, 2014). That said, for a student not intending to pursue chemistry beyond A-level, Core Maths would be preferable to no mathematics. In reality, at the point of embarking on A-level studies, many students are still uncertain about their post-18 plans.

The analysis shows that the volume and complexity of algebraic thinking in A-level physics is radically different from that required elsewhere and that without exceptional prior performance at GCSE (i.e. an A* grade) or the improved facility with algebraic manipulation afforded by Alevel Mathematics, the mathematical content of A-level Physics is going to prove challenging. Combining the study of A-level Physics and A-level Mathematics should facilitate a student's progress in this area. Furthermore, there are also potential overlaps for those studying both subjects in areas such as mechanics. (The reformed A-level Mathematics which students will take from 2017 will include compulsory mechanics for all students (DfE, 2016). At the time of writing, this is not the case.) However, we do recognise that the approaches to mechanics questions may differ substantially between the two subjects, and students may not immediately grasp the more subtle inter-related connections between the two.

As befits an implicit GCSE Mathematics prerequisite for A-level Physics, our analysis of the Physics SAMs did not, in general, encounter calculus, although the language of rates of change and the notation of increments did arise very occasionally. However, the Institute of Physics (IOP) investigation of the mathematical needs of first year physics and engineering degrees highlighted the important of calculus for the study of physics in university (IOP, 2011). This is further emphasised in the IOP university degree accreditation requirements ${ }^{1}$. As such, the study of A-level Mathematics is essential for those wishing to continue their studies in physics at university.

Our analysis of the SAMs in physics did identify examples of real-life scenarios. In some of the examination papers there was also clear evidence of a requirement for problem solving, although we did not probe in detail the question of whether or not this arose uniformly across awarding organisations. The problem solving aspect of the reformed A-level Physics qualifications is worthy of note since the enjoyment of problem solving was a reason given by undergraduate mathematics students for favouring to study mathematics in preference to physics at university (IOP, 2011). We present this information to the reader with a note of caution given that there has

\footnotetext{
${ }^{1}$ https://www.iop.org/education/higher education/accreditation/file 64166.pdf
} 
been considerable concern over the reduction in problem solving in public examinations in mathematics over the last 50 years (ACME, 2016).

Decisions about the best form of mathematics to study would ideally be taken with some understanding of the mathematical demands of a particular A-level science but also of the expectations following the transition into university in that subject. Our analysis shows that whilst the move to include mathematics in A-level sciences is laudable, it only goes part way to addressing the mathematical continuity requirements between school and university sciences. Each of the subjects analysed offer limited opportunity for the assessment of threshold concepts/practices for university study, for example, algebra in biology and calculus in physics. It is therefore clear that whilst these new science specifications encourage the use of mathematics in context, the further development of mathematical competencies and confidence in parallel mathematics qualifications is also necessary.

Our study has focussed on the initial implementation phase of the recent embedding policy that prescribes statutory requirements for the percentage of marks assessing mathematics within Alevel sciences. In parallel, the adding policy that is encouraging all young people to study mathematics to 18 has precipitated the introduction of new qualifications (e.g. Core Maths), thereby increasing the opportunities for mathematical study that can support the sciences. We also draw attention to the need for funding models to support students taking post-16 mathematical qualifications in parallel with A-level study. Not all students in the sciences may wish to study mathematics as one of their subjects at A-level. Funding models should neither prohibit students from taking other mathematics qualifications nor act as any form of disincentive to schools offering them. In conclusion, there is unquestionably a need for sustained progress in both policy directions and we hope that the evidence we have presented here will contribute to further debate in this area.

\section{References}

ACME. (2011). Mathematical needs: mathematics in the workplace and in higher education. Retrieved from London: http://www.acmeuk.org/media/7624/acme theme a final\%20(2).pdf

ACME. (2012). Post-16 Mathematics: a strategy for improving provision and participation. Retrieved from London: http://www.acmeuk.org/media/10520/20121217acme post_16 strategy.pdf

ACME. (2016). Problem solving in mathematics: realising the vision through better assessment. London: Advisory Committee on Mathematics Education / Royal Society. 
Adkins, M., \& Noyes, A. (2017). Do Advanced Mathematics Skills Predict Success in Biology and Chemistry Degrees? International Journal of Science and Mathematics Education, in press. doi: 10.1007/s10763-016-9794-y

Ball, S., Maguire, M., \& Macrea, S. (2000). Choice, Pathways and Transitions Post-16: New Youth, New Economics in the Global City. London: RoutlegeFalmer.

Briggs, A. R. J., Clark, J., \& Hall, I. (2012). Building bridges: understanding student transition to university. Quality in Higher Education, 18(1), 3-21. doi:10.1080/13538322.2011.614468

Browne, R., Koenig, J., MacKay, N., Sheldon, N., Sillcot, N., \& Wake, G. (2013). Report from the expert panel on Core Maths. Retrieved from London: http://www.acmeuk.org/media/13699/final $\% 2007$ october $2013, \% 20$ expert $\% 20$ panel $\% 20$ on $\% 20$ core $\% 20 \mathrm{~m}$ athematics $\% 20$ report.pdf

CBI. (2009). Stronger together: businesses and universities in turbulent times. Retrieved from London: https://globalhighered.files.wordpress.com/2009/09/cbi he taskforce report.pdf

DfE. (2013). Mathematics: GCSE subject content and assessment objectives. Retrieved from London.

DfE. (2014). GCE AS and A level subject content for biology, chemistry, physics and psychology. London.

DfE. (2016). Mathematics: AS and A level content. London.

Gago, J. M. (2004). Increasing human resources for science and technology in Europe. Brussels: European Commission.

Gove, M. (2011). Michael Gove speaks to the Royal Society on maths and science. Retrieved from http://www.education.gov.uk/inthenews/speeches/a00191729/michael-gove-speaksto-the-royal-society-on-maths-and-science

Hargreaves, L., \& Galton, M. (2002). Transfer and Transition. In L. Hargreaves \& M. Galton (Eds.), Transfer from the primary classroom: 20 years on (pp. 1-27). London:

Routledge Falmer.

Harris, D., Black, L., Hernandez-Martinez, P., Pepin, B., Williams, J., \& with the TransMaths, T. (2015). Mathematics and its value for engineering students: what are the implications for teaching? International Journal of Mathematical Education in Science and Technology, 46(3), 321-336. doi:10.1080/0020739x.2014.979893

Harris, J. (2012). Rational Numbers: investigating compulsion for mathematics study to 18. Retrieved from London: http://thepearsonthinktank.com/2012/rational-numbersinvestigating-compulsion-for-mathematics-study-to-18/

Hernandez-Martinez, P., Black, L., Williams, J., Davis, P., Pampaka, M., \& Wake, G. (2008). Mathematics students' aspirations for higher education: class, ethnicity, gender and interpretive repertoire styles. Research Papers in Education, 23(2), 153-165.

Hodgen, J., Marks, R., \& Pepper, D. (2013). Towards universal participation in post-16 mathematics lessons from high-performing countries. London: Nuffield Foundation.

Hodgen, J., McAlinden, M., \& Tomei, A. (2014). Mathematical transitions: a report on the mathematical and statistical needs of students undertaking undergraduate studies in various disciplines. York: Higher Education Academy.

Hodgen, J., Pepper, D., Sturman, L., \& Ruddock, G. (2010). Is the UK an Outlier? London: Nuffield Foundation.

House of Lords. (2012). Higher Education in Science, Technology, Engineering and Mathematics (STEM) subjects. Report No. 37. London. 
Hulme, J., \& Wilde, J. d. (2014). Tackling transition in STEM disciplines: Supporting the Science, Technology, Engineering and Mathematics (STEM) student journey into higher education in England and Wales. York: Higher Education Academy.

IOP. (2011). Mind the gap: mathematics and the transition from A-level to physics and engineering degrees. London: Institute of Physics.

Jones, I., Wheadon, C., Humphries, S., \& Inglis, M. (2016). Fifty years of A-level mathematics: have standards changed? British Educational Research Journal, 42, 543-560. doi:10.1002/berj.3224

Koenig, J. (2011). A survey of the mathematics landscape within bioscience undergraduate and postgraduate UK higher education. Leeds: http://www.bioscience.heacademy.ac.uk/ftp/reports/biomaths landscape.pdf

Koenig, J. (2012). The mathematics landscape in bioscience undergraduate and postgraduate UK higher education. York: Higher Education Academy.

Kounine, L., Marks, J., \& Truss, E. (2008). The Value of Mathematics. London: REFORM.

Matthews, A., \& Pepper, D. (2007). Evaluation of Participation in A level Mathematics: final report. London: Qualifications and Curriculum Authority.

Mendick, H. (2008). Subtracting difference: troubling transitions from GCSE to AS-level mathematics. British Educational Research Journal, 34(6), 711-732.

National Academies. (2007). Rising above the gathering storm: energizing and employing America for a brighter future. Washington, DC: The National Academies Press.

National Strategic Review of Mathematical Sciences Research in Australia. (2006). Mathematics and statistics: critical skills for Australia's Future. Canberra.

Nicholls, G., \& Gardner, J. (1999). Pupils in Transition: Moving between Key Stages. London: Routledge.

Noyes, A. (2006). School Transfer and the Diffraction of Learning Trajectories. Research Papers in Education, 21(1), 43-62.

Noyes, A., \& Adkins, M. (2016b). The Impact of Research on Policy: A Case of Qualifications Reform. British Journal of Educational Studies, 35(1), 1-13. doi:10.1080/00071005.2016.1159654

Noyes, A., \& Adkins, M. (2016a). Reconsidering the rise in A-Level Mathematics participation. Teaching Mathematics and its Applications, 64, 449-465. doi:10.1093/teamat $/ \mathrm{hrv016}$

Noyes, A., Drake, P., Wake, G., \& Murphy, R. (2010). Evaluating Mathematics Pathways: Final Report, December 2010 Retrieved from https://www.education.gov.uk/publications/standard/publicationDetail/Page1/DFE$\underline{\mathrm{RR} 143}$

Noyes, A., Wake, G., \& Drake, P. (2011). Widening and increasing post-16 mathematics participation: pathways, pedagogies and politics. International Journal of Science and Mathematics Education, 9, 483-501.

Noyes, A., Wake, G., \& Drake, P. (2013). Time for curriculum reform: the case of mathematics. The Curriculum Journal, 24(4), 511-528. doi:10.1080/09585176.2013.812973

Nuffield. (2012). Mathematics in A level assessments. London: The Nuffield Foundation.

Pampaka, M., Williams, J., \& Hutcheson, G. (2012). Measuring students' transition into university and its association with learning outcomes. British Educational Research Journal, 38(6), 1041-1071. doi:10.1080/01411926.2011.613453 
Rice, J. K. (2001). Explaining the negative impact of the transition from middle to high school on student performance in mathematics and science. Educational Administration Quarterly, 37(3), 372-400.

Royal Society. (2011). Preparing for the transfer from school and college science and mathematics education to UK STEM higher education. London: Royal Society.

RSS/ACME. (2015). Embedding Statistics at A level: a report on statistical requirements and assessment across A level courses in Biology, Business, Chemistry, Geography, Psychology and Sociology. London.

SCORE. (2012). Mathematics within A-level science examinations. London: Science Community Representing Education.

Shallcross, D. E., \& Yates, P. C. (2014). Skills in mathematics and statistics in chemistry and tackling transition. York: Higher Education Academy.

Vorderman, C., Budd, C., Dunne, R., Hart, M., \& Porkess, R. (2011). A world-class mathematics education for all our young people. Retrieved from http://www.tsmresources.com/pdf/VordermanMathsReport.pdf 